British Journal of Environmental Sciences

Vol.10, No.2, pp. 13-22, 2022

ISSN 2054-6351 (print),

ISSN 2054-636X (online)

\title{
AN EXAMINATION OF THE PROBLEMS ENCOUNTERED IN APPLYING QUALITY ASSESSMENT SYSTEM BY LAGOS STATE BUILDING CONTRACTORS
}

\author{
Ngozi Marykate Okoye, Kevin Chuks Okolie ; Okongwu Ikechukwu Michael
}

Department of Building, Nnamdi Azikiwe University, Awka-Anmabra State

\begin{abstract}
The construction industry contributes 1\% employment opportunities to Nigerians (Ding, 2008). According to the World Bank, an active industry should contribute at least $3.2 \%$ of the employment opportunities in the country. The aim of this study is to examine the problems encountered in applying quality assessment system in Lagos state. In order to realize this aim, the study examined challenges encountered by contractors..The study employed a descriptive case study design where data was collected from senior managers, project managers, engineers, architects, quantity surveyors, and technical managers working with building construction companies in the Lagos Metropolitan Area using the mixed method approach. Quantitative data was collected using questionnaire from 109 randomly selected participants and analysed using descriptive and inferential statistics. Qualitative data was collected through interviews with 9 purposively selected respondents and analysed using the thematic analysis technique. The study shows challenges encountered by Contractors to include: Lack of adequate resources, inadequate skills and expertise, Casual/ temporary nature of construction workforce, Internal resistance, Lack of flexibility in existing tools and approaches etc. The study concludes that the most significant challenge encountered by local contractors when it comes to quality assessment is the lack of adequate resources and the study also identified staff training and education, integration of information technology, and increased involvement of senior leaders as the most important issues that they would like their organization to improve so as to increase the effectiveness of the quality assessment process.
\end{abstract}

KEYWORDS: Examination, quality, assessment, system, Lagos State, building contractors.

\section{INTRODUCTION}

The construction industry contributes $1 \%$ employment opportunities to Nigerians (Ding, 2008). According to the World Bank, an active industry should contribute at least 3.2\% of the employment opportunities in the country (Elinwa \& Joshua, 2001). According to Idiake, Shittu, Anunobi, \& Akanmu, (2015), the construction industry in Nigeria can create more jobs if it upholds quality. Despite overall growth and good performance, Shittu, Idiake, and Akanmu, (2015) observe that the last decade was characterized by declining level of clients' satisfaction with the built facilities due to perceived poor quality. In addition to quality, other major problems affecting the clients' perception and overall performance of the industry include time and cost overruns (Oladinrin $\&$ Ho, 2015). In this regard, it is imperative for leaders in the construction industry in Nigeria, including financiers of construction projects and government agencies responsible for overseeing and monitoring these projects to introduce radical change in industry practice in order to guarantee

ECRTD-UK https://www.eajournals.org/

Journal level DOI: https://doi.org/10.37745/bjes.2013 
quality (Rashvand, Majid \& Pinto, 2015). This can be done through the development of a quality evaluation methodology to analyze, gauge and rate the performance of different contractors. Clients will naturally select contractors with high rating or reputation in the industry and this would encourage small and less reputable contractors to undergo internal reorganization and change in order to achieve better rating and thus higher reputation which attracts more clients (Woon, Mohammad, Baba, Zainol \& Nazri, 2015).

\section{LITERATURE REVIEW}

Despite the challenges, implementing an effective quality assessment system presents numerous benefits to construction projects including minimizing mistakes, material wastage, and rework; enhancing control over suppliers and subcontractors; increasing productivity and profitability, and expanding market share (Leong et al., 2014).

Despite the development of a wide variety of quality management systems for use in the construction industry, quality problems are still widespread. A significant factor that led to the persistence of quality issues is deficiency in the implementation of existing QAS. Another factor is unwillingness on the part of construction companies to implement these QAS due to the challenges associated with them (Hoonakker, Carayon, \& Loushine, 2010). Understanding challenges experienced in the implementation of quality system by building contractor will assist in the development of guidelines for ensuring effective implementation. A significant barrier to the implementation of QAS is lack of flexibility. Kaziliunas (2012) found that one of the problems that hinder the implementation of ISO 9000 is lack of flexibility in the design and implementation of these systems. The author noted that organizations are usually of different size, have different structures, and apply different strategy. Organizations are also exposed to different political, economic, social, technological, and competitive factors. Consequently, QAS cannot work the same way in all organizations. Many organizations fail to implement QAS successfully because they lack the ability to adjust and modify these systems to suit their internal and external environments. This point is also emphasized by Fraga, Fukutani, Celes, Barral, and Oliveira (2010), who asserted that for any system to be functional, it has to be open and dynamic. It must have the capacity to respond to uncertainty and rapid changes in the business environment. Another problem that affects the implementation of QAS is lack of adequate resources. The implementation of QAS requires resources in the form of material, equipment, manpower, and skills. Absence of any of these resources affects the implementation process. This claim is confirmed in a study by Anup, Kumar, and Saqhi (2015), where it was found that the implementation of ISO based systems in the Indian construction industry was hindered by inadequate allocation of funds and insufficient technical skills on the part of employees. Taner (2013) also found that lack of knowledge and skills was a significant barrier to the implementation of Six Sigma based QMS in large scale construction firms in Turkey. Hoonakker, Carayon, and Loushine, (2010) also found that the dwindling of profits margin caused by increased competition in the construction industry has compelled a large number of contractors in the United States to reduce the amount of resources allocated towards quality and safety management. 
The nature of construction workforce is also a significant barrier to the implementation of QAS. In most construction companies, workers are recruited at the project site on a temporary or casual basis (Haupt \& Whiteman, 2014). These workers are hardly retained when the company moves to another project. Such labor practices make it difficult to implement QAS especially those that emphasize active involvement of staff and continuous learning. The casual nature of the workforce means that most employees are rarely involved in the development of project plans. Limited employee retention also hinders the process of learning and transferring lessons from one project to another. In addition, the labor practices in the construction industry hinder the application of QAS by negatively affecting employees' motivation and engagement levels (Osabiya, 2015). Casual and short-term employment contracts affect employees' job security and their level of organizational commitment result in low motivation and engagement.The implementation of QAS in the construction industry is also hampered by complex contractual relationships that typify this industry. The implementation of most QAS requires a holistic approach that involves all project stakeholders (Kim, Kumar, \& Kumar, 2011). The requirement is often difficult to implement because construction projects comprise of so many stakeholders and players. One reason behind this trend is that construction projects comprise of a wide variety of tasks including structural design, construction, plumbing, building wiring, and interior design among others (Ke, Ling, and Zou, 2014). These tasks are rarely completed by a single entity; hence, complex contractual and subcontracting relationships are often developed. In addition, construction projects require a wide range of inputs such as cement, steel, bricks, paint, electrical installation, plumbing equipment, and sand among others (Enshassi, Mohamed, Abushaban, 2009). Consequently, building contractors have to develop contractual relationships with a large number of suppliers. It becomes so difficult to mobilize and engage all these players in the implementation of QASs.

As noted by Hoonakker, Carayon, and Loushine, (2010), the relationship between the main contractor, subcontractor, and supplier is often not clear. It is a common occurrence to find a supplier being selected by a subcontractor. For instance, an entity that is subcontracted to do the wiring tasks may select its own supplier of electrical equipment and fitting. In such a scenario, the main building contractor may not have an influence over the supplier. Some subcontractors and suppliers may show little interest in the quality processes and procedures being introduced (Haupt \& Whiteman, 2014). Since the main contractor does not have direct control over the activities of the suppliers and subcontractors, it becomes difficult to compel them to adhere to quality mechanisms. In addition, one may find a situation where the main contractor is large, but the subcontractors and suppliers are small; hence, they lack adequate resources and capacity to implement quality mechanism and procedures.Complex contractual relationships not only affect the implementation of QAS, but also have an impact on project outcome. The claim was reinforced in a study by Ke, Ling, and Zou (2014), where project performance indicators such as client satisfaction and cost were correlated against the contractual practices of a sample of construction companies in Sydney, Australia. Findings revealed that there was a statistically significant relationship between contracting practices and project performance. Enshassi, Mohamed, and Abushaban (2009) also found continuous collaboration and coordination between the general contractors and other project participants was an essential determinant of the performance of construction projects in the Gazza Strip. Results revealed that the main causes of poor project 
performance in the region were delay in delivery of material and delivery of poor material. This finding highlights the importance of contractual relationship in ensuring excellence in delivery of projects.

Internal resistance is also a major barrier to the implementation of QAS. The implementation of most QAS requires radical changes in organizational structures, processes, and way of doing things (Rangelova and Traykova, 2014; Nelson et al., 2011). Change brings about uncertainty; hence, is bound to elicit resistance from employees. Internal resistance may also arise from employees' attitude regarding the QAS being implemented. If not managed appropriately, internal resistance can be a significant barrier to the effective implementation of QASs. In his study, Taner (2013) found that internal resistance was among the top two factors that barred the successful implementation of Six Sigma projects in the Turkey construction industry. Cachadina (2009) also found that the implementation of QAS in small and medium sized construction firms often require systematization and structuring of processes. This task often met with resistance as it formalizes a specific authority and increases employees' accountability. Another significant barrier to QAS implementation is lack of strong support from senior management. Senior managers play a vital role in the implementation of quality management system. Managers not only ensure that there is adequate resources for implementing QAS, but also provide the vision and road map for guiding other members of the organization (Keng \& Hamzah, 2011). Senior managers also act as role model for other members of the organization where quality management is concerned. Consequently, inadequate support from the management during the implementation of QAS hinders the effectiveness of the process. Haupt and Whiteman (2014) argues that success in the management of quality can only be realizes when top management 'buys in' to the changes involved. In addition, upper management must have the willingness and capacity to introduce and implement quality management initiatives.

The study by Keng (2010) examined the level of commitment of the senior management team towards quality management between Malaysian construction companies with and without ISO 9000 certification. The study utilized a descriptive survey design where data was collected using questionnaires. Findings revealed that top managers in organizations with ISO certification had higher level of commitment towards quality management than their counterparts from the perspectives of resource allocation, attitude towards change, involvement in quality effort, and faith in quality goals. Aziz and Hafez (2013) found that leadership commitment was an essential factor in the implementation of the Last Planner System in the Egyptian construction sector. Another major barrier in the implementation of QAS is too much documentation. This was revealed in a study by Anup, Kumar, and Saqhi (2015), where respondents expressed discontent with the amount of paper work involved in the implementation of quality systems. There was concern that too much documents distracts employees from executing job related tasks. In the study by Haupt and Whiteman (2014), respondents lamented that most construction projects already involve a lot of paper work including steel bending schedules, architects' instructions, records of plans, contract documents, and material safety and data sheets. The implementation of QAS system adds to the already burden volume of documentation. 


\section{METHODOLOGY}

This study will employ descriptive cross-sectional case study design, this cross-sectional design is selected to understand the current situation in the Lagos construction industry with regard to quality assessment rather than test the effect or a program. The target population comprises of senior managers, project managers, technical managers, architects, quantity surveyors, and engineers working with building contractors operating the Lagos Metropolitan Area, these are selected because they are actively involved in the planning and management of construction projects; hence, they are likely to provide the information needed to answer the research questions. Survey revealed that 1771 construction companies was registered in Lagos ( Public Procurement Agency, Alausa Ikeja, 2018) . 1000 construction companies are from LMA which comprises 13 local government area. The population of his study is 1000 construction companies. This study made use of the Taro Yamane sample size formulae to determine the appropriate sample size for collection of quantitative data:

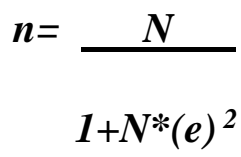

Where $\mathrm{N}=$ Population, $\mathrm{n}=$ Sample size and $\mathrm{e}=$ Margin of error

Since the unit of analysis is the building construction company, the number of registered building construction companies in Lagos Metropolitan Area will serve as population size. The population size is 1000 . The margin of error is set at $5 \%$. Using the formulae, the desired sample size would be:

$\mathrm{n}=1000 /\left[1+\left\{1000 *(0.05)^{2}\right\}\right]$

$\mathrm{n}=285.7 \approx 286$ companies.

The purposive sampling technique is adopted as it entails selecting participants based on the researcher's judgment regarding his or her ability to provide the require information. The audiorecorded Interview is the main method of data collection which took between 30 and 45 minutes depending on the level of details provided on the quality assessment methods that are currently used in their organizations, how these methods impact performance, challenges involved in implementing quality systems, and factors critical to the successful implementation of a QAS. Questionnaires to 100 building construction companies operating in the Lagos Metropolitan Area. The first instrument of data collection is a semi-structured interview guide selected because of its ability to facilitate the collection of rich and contextual information, which is in line with the goal of the study while the structured questionnaires comprises of multiple choice questions to collect quantitative data via clustered random sampling method. The transcript for each interview will be 
Vol.10, No.2, pp. 13-22, 2022

ISSN 2054-6351 (print),

ISSN 2054-636X (online)

analysed using t-tests to measures the impact of quality assessment system on project delivery in Lagos while the Principal Component Analysis (PCA) is used to reduce the number of variables while retaining the original variance as possible. Th method is to determine the method and approaches that the Lagos contractors are currently using to assess quality in their organizations as well as the major problem facing building contractors in applying quality assessment systems in Lagos, Nigeria. For internal validity, the researcher discussed the questions contained in the research instruments, design and method used in data collection and analysis with the experts to ensure that they capture what the study intends to measure. For external validity to enhance the generalizability of findings, the researcher documented the study methods and procedures in a clear and elaborate fashion. The reliability of the study was enhanced by conducting a pilot study before the main data collection exercise. The pilot involved a total of 10 builders and utilized the test retest approach. The responses for the first and second round were compared using the Pearson Product Moment Correlation Coefficient at a threshold of 0.7. The test yielded a correlation coefficient of 0.87 leading to the conclusion that the instrument is highly reliable.

\section{RESULTS AND FINDINGS}

Another objective of the study was to examine the challenges that hinder indigenous building contractors in Nigeria from conducting the quality assessment role effectively. To realize this objective, participants were presented with a list of challenges and asked to rate them on a scale of 1-10 with 1 indicating that the challenge has very little effect on effectiveness of QA and 10 indicating that the factor hinders the effectiveness of QA to a great extent. Responses were analyzed using the Friedman Rank method. Results are presented in Table 4.1:

Table 4.1: Ranking of QA Challenges using the Friedman Method

\begin{tabular}{llll}
\hline Rank & Factor & N & Mean Rank \\
\hline 1 & Lack of adequate resources & 261 & 6.72 \\
2 & Inadequate skills and expertise & 261 & 6.48 \\
3 & Casual/ temporary nature of construction workforce & 261 & 6.13 \\
4 & Internal resistance & 261 & 5.65 \\
5 & Lack of flexibility in existing tools and approaches & 261 & 3.41 \\
6 & Too much documentation & 261 & 3.39 \\
7 & Complex contractual relationships & 261 & 3.16 \\
8 & Lack of adequate support from senior managers & 261 & 2.97 \\
\hline
\end{tabular}

Source: Field Survey, 2017

Lack of adequate resource emerged as the highest ranked among factors that hinder effectiveness of QA processes within the sampled organizations. This result is consistent with the study by Anup 
et al. (2015) where it was found that the implementation of ISO based systems in the Indian construction industry was hindered by inadequate allocation of funds and insufficient technical skills on the part of employees. The second highest ranked factor is inadequate skills and expertise on the part of construction workers. This position is supported by Taner (2013) who found that majority of players in the Lagos construction industry lack adequate knowledge regarding quality assessment tools and methods especially statistic and technology based methods. This lack of knowledge and skills is a significant barrier to the implementation of QAS as practitioners are compelled to rely on subjective and less reliable methods. Another challenge that was deemed to influence the effectiveness of the QA process to a great extent was the casual or temporary nature of the construction workforce. As Haupt and Whiteman (2014) explained, most construction companies recruit workers at the project site on a temporary or casual basis (Haupt \& Whiteman, 2014). These workers are hardly retained when the company moves to another project. Such labor practices make it difficult to implement QAS especially those that emphasize active involvement of staff and continuous learning. It also makes it difficult to engage lower level employees in quality planning, as well as, to foster learning and transfer of skills (Osabiya, 2015). Internal resistance was also ranked highly among the list of challenges that the contractors experience in the process of assessing quality. This position is supported by Rangelova and Traykova, who noted that implementing a QAS requires radical changes in organizational structures, processes, and way of doing things. This radical changes cause uncertainty and feat among internal stakeholders leading to the development of resistance. The study by Taner (2013) also revealed that internal resistance was among the top two factors that barred the successful implementation of Six Sigma projects in the Turkey construction industry. Cachadina (2009) also found that the implementation of QAS in small and medium sized construction firms was often met with resistance as it formalizes a specific authority and increases employees' accountability. Lack of flexibility of existing tools and methods was ranked fifth in the list of eight challenges presented to the participants. This implies that the majority of the respondents felt that this factors was less significant that the first four. Nonetheless, the idea that lack of flexibility of existing QAS can hinder the assessment process is supported by Kaziliunas (2012) who noted that many organizations fail to implement QAS successfully because they lack the ability to adjust and modify these systems to suit their internal and external environments. Too much documentation, complex contractual relationships, and lack of adequate managerial support were ranked $6^{\text {th }}, 7^{\text {th }}$, and $8^{\text {th }}$ respectively suggesting that participants felts that the other factors were more pressing.

\section{CONCLUSION}

The most significant challenge encountered by local contractors when it comes to quality assessment is the lack of adequate resources. It became apparent that scarcity of resources compels the local contractors to limit their quality assessment activities to only issues that are required by regulations. Other challenges that were highly ranked include lack of skills and expertise, the casual/ temporary nature of the construction workforce, and internal resistance in that order. Participants also identified staff training and education, integration of information technology, and 
Vol.10, No.2, pp. 13-22, 2022

ISSN 2054-6351 (print),

ISSN 2054-636X (online)

increased involvement of senior leaders as the most important issues that they would like their organization to improve so as to increase the effectiveness of the quality assessment process. (See table 4.1).Generating an understanding of the challenges that local contractors in Lagos experience when it comes of quality assessments. The study has established some of the factors that hinder local contractors in Lagos from performing the quality assessment role effectively. Major challenges that were identified include lack of adequate resources, in adequate skills and expertise, temporary nature of the construction workforce, and internal resistance. This knowledge presents top stakeholders' a basis for developing future programs and interventions aimed at improving quality assessment in the Lagos construction industry.

\section{REFERENCES}

Ding, G. K. (2008). Sustainable construction-The role of environmental assessment tools. Journal of environmental management, 86(3), 451-464.

Anup, W., Kumar, A., \& Saqhi, N. (2015). Study of quality management system in construction. International Research Journal of Engineering and Technology, 2 (2), $462-467$.

Taner, M. (2013). Critical success factors for Six-Sigma implementation in large-scale Turkish construction companies. International Review of Management and Marketing, 3 (4), 212225.

Fraga, H., Fukutani, K., Celes, F., Barral, A., \& Oliveira, C. (2012). Evaluation of the implementation of a quality system in a basic research laboratory: Viability and impact. Health Economics and Management, 10 (4), 41-49.

Kaziliunas, A. (2012). Problems while implementing quality management systems for a sustainable development of organizations. Public Policy and Administration, 34 (1), 71 82.

Hoonakker, P., Carayon, P., \& Loushine, T. (2010). Barriers and benefits of quality management in the construction industry: An empirical study. Total Quality Management, 21 (9), 953969.

Kaziliunas, A. (2012). Problems while implementing quality management systems for a sustainable development of organizations. Public Policy and Administration, 34 (1), 71 82.

Cachadina, N., (2009). Implementing quality management systems in small and medium construction companies: A contribution to a road map for success. Leadership Management and Engineering, 9 (1), 32- 39.

Rangelova, F., \& Traykova, M. (2014). Value management in construction project. $1^{\text {st }}$ Applied Science Conference. Sofia, Bulgaria.

Osabiya, J. (2015). The effect of employees' motivation on organizational performance. Journal of Public Administration and Policy Research, 7 (4), 62- 75.

Taner, M. (2013). Critical success factors for Six-Sigma implementation in large-scale Turkish construction companies. International Review of Management and Marketing, 3 (4), 212225.

Anup, W., Kumar, A., \& Saqhi, N. (2015). Study of quality management system in construction. International Research Journal of Engineering and Technology, 2 (2), 462- 467.

ECRTD-UK https://www.eajournals.org/

Journal level DOI: https://doi.org/10.37745/bjes.2013 
British Journal of Environmental Sciences

Vol.10, No.2, pp. 13-22, 2022

ISSN 2054-6351 (print),

ISSN 2054-636X (online)

Haupt, T., \& Whiteman, D. (2014). Implementing total quality management on construction sites. Academy of Management Journal, 44 (1), 258- 269.

Anup, W., Kumar, A., \& Saqhi, N. (2015). Study of quality management system in construction. International Research Journal of Engineering and Technology, 2 (2), 462- 467.

Aziz, R., \& Hafez, S. (2013). Applying lean thinking in construction and performance improvement. Alexandria Engineering Journal, 52 (4), 679- 695.

Anup, W., Kumar, A., \& Saqhi, N. (2015). Study of quality management system in construction. International Research Journal of Engineering and Technology, 2 (2), 462- 467.

Aziz, R., \& Hafez, S. (2013). Applying lean thinking in construction and performance improvement. Alexandria Engineering Journal, 52 (4), 679- 695.

Haupt, T., \& Whiteman, D. (2014). Implementing total quality management on construction sites. Academy of Management Journal, 44 (1), 258- 269.

Keng, T., \& Hamzah, A. (2011). Study of quality management in construction projects. Chinese Business Review, 10 (7), 542- 552.

Cachadina, N., (2009). Implementing quality management systems in small and medium construction companies: A contribution to a road map for success. Leadership Management and Engineering, 9 (1), 32- 39.

Taner, M. (2013). Critical success factors for Six-Sigma implementation in large-scale Turkish construction companies. International Review of Management and Marketing, 3 (4), 212225.

Nelson, M., Lee, A., Cooper, R., Kagioglou, M., \& Fleming, A. (2011). Process reengineering in the construction industry: Buzzword or reality? Business Process Management, 3 (1), 6480 .

Rangelova, F., \& Traykova, M. (2014). Value management in construction project. $1^{\text {st }}$ Applied Science Conference. Sofia, Bulgaria.

Enshassi, A., Mohamed, S., \& Abushaban, S. (2009). Factors affecting the performance of construction projects in the Gaza Strip. Journal of Civil Engineering and Management, 15 (3), 269- 280.

Ke, Y., Ling, F., \& Zou, P. (2013). Effects of contract strategy on interpersonal relations and project outcomes of public-sector construction contracts in Australia. Journal of Management and Engineering, 31 (4), 284- 301.

Kim, D., Kumar, V., \& Kumar, U. (2011). A performance realization framework for implementing ISO 9000. International Journal of Quality \& Reliability Management, 28 (4), 383- 404.

Osabiya, J. (2015). The effect of employees' motivation on organizational performance. Journal of Public Administration and Policy Research, 7 (4), 62- 75.

Haupt, T., \& Whiteman, D. (2014). Implementing total quality management on construction sites. Academy of Management Journal, 44 (1), 258- 269.

Leong, T., Zakuan, N., Saman, M., Ariff, S., \& Tan, C. (2014). Using project performance to measure effectiveness of quality management system maintenance and practices in construction industry. The Scientific World Journal, 5 (1), 1-9.

Woon, N. B., Mohammad, I. S., Baba, M., Zainol, N. N., \& Nazri, A. Q. (2015). Critical Success Factors for Post Occupancy Evaluation of Building Performance: A Literature Analysis. Jurnal Teknologi, 74(2).

ECRTD-UK https://www.eajournals.org/

Journal level DOI: https://doi.org/10.37745/bjes.2013 
Vol.10, No.2, pp. 13-22, 2022

ISSN 2054-6351 (print), ISSN 2054-636X (online)

Rashvand, P., Majid, M. Z. A., \& Pinto, J. K. (2015). Contractor management performance evaluation model at prequalification stage. Expert Systems with Applications, 42(12), 5087-5101.

Oladinrin, O. T., \& Ho, C. M. (2015). Critical Enablers for Codes of Ethics Implementation in Construction Organizations. Journal of Management in Engineering, 04015023.

Shittu, A. A., Idiake, J. E., \& Akanmu, W. P. (2015). Effect of Petroleum Price Increase on Cost of Selected Building Finishing Materials in the Lagos Construction Industry (2006-2012). Journal of Economics and Sustainable Development, 6(8), 141-150.

Idiake, J. E., Shittu, A. A., Anunobi, A. I., \& Akanmu, W. P. (2015). A Comparative Analysis of Traditional and Design \& Build Methods of Procurement in the Lagos Construction Industry. International Journal of Construction Engineering and Management, 4(1), 1-12.

Elinwa, A. U., \& Joshua, M. (2001). Time-overrun factors in Lagos construction industry. Journal of construction engineering and management, 127(5), 419-425. 